\title{
RESEARCH
}

\section{GABPA-dependent down-regulation of DICER1 in follicular thyroid tumours}

\author{
Johan O Paulsson1,3,*, Na Wang1,*, Jiwei Gao1, Adam Stenman1,2,3, Jan Zedenius²,3, Ninni Mu1', Weng-Onn Lui1, \\ Catharina Larsson ${ }^{1}$ and C Christofer Juhlin ${ }^{1,4}$ \\ 'Department of Oncology-Pathology, Karolinska Institutet, Karolinska University Hospital, Stockholm, Sweden \\ 2Department of Molecular Medicine and Surgery, Karolinska Institutet, Karolinska University Hospital, Stockholm, Sweden \\ ${ }^{3}$ Department of Breast, Endocrine Tumours and Sarcoma, Karolinska University Hospital, Stockholm, Sweden \\ ${ }^{4}$ Department of Pathology and Cytology, Karolinska University Hospital, Stockholm, Sweden
}

Correspondence should be addressed to J O Paulsson or C C Juhlin: johan.paulsson@ki.se or christofer.juhlin@ki.se

*(J O Paulsson and N Wang contributed equally to this work)

\begin{abstract}
Mutations in the miRNA enzyme gene DICER1 have been reported in several endocrine malignancies and is associated with the rare tumour-predisposing DICER1 syndrome. DICER1 mutations have been reported in subsets of follicular thyroid carcinoma (FTC), but the role of DICER1 in follicular thyroid tumorigenesis has not been extensively studied. In this study, we investigate the role of DICER1 in 168 follicular thyroid tumours and in an FTC cell line. We found rare DICER1 mutations in paediatric FTC cases and a general DICER1 down-regulation in FTCS visualized both on mRNA and protein level, especially pronounced in Hürthle cell carcinoma (HuCC). The down-regulation was also evident in follicular thyroid adenomas (FTAs), suggesting a potential early step in tumorigenesis. The expression of DICER1 was lower in FTCS of older patients in which TERT promoter mutations are more frequent. In FTCS, DICER1 down-regulation was not caused by gene copy number loss but significantly correlated to expression of the transcription factor GABPA in clinical cases. GABPA was found to bind to the DICER1 promoter and regulate DICER1 expression in vitro, as GABPA depletion in FTC cell lines reduced DICER1 expression. This in turn stimulated cell proliferation and affected the miRNA machinery, evident by altered miRNA expression. To conclude, we show that GABPA directly regulates DICER1 in FTC, acting as a tumour suppressor and displaying down-regulation in clinical samples. We also show reduced expression of DICER1 in benign and malignant follicular thyroid tumours, suggesting a potentially early tumorigenic role of this gene aberrancy.
\end{abstract}

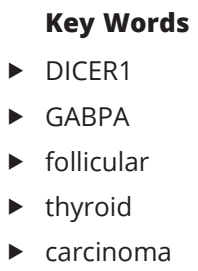

Endocrine-Related Cancer (2020) 27, 295-308

\section{Introduction}

Thyroid cancer is the most common endocrine malignancy and accounts for about $1-3 \%$ of all new cases of cancers and occurs predominantly in women (Siegel et al. 2018). The incidence of thyroid cancer has steadily increased for the last few decades, especially since the beginning of the 1990s, but the mortality rate has remained relatively stable (Kitahara \& Sosa 2016). The increase is mainly attributable to the increasing incidence of papillary thyroid carcinoma (PTC), but all forms show an increase (Davies \& Welch 2014, Carlberg et al. 2016, Kitahara \& Sosa 2016, Cronin et al. 2018). Follicular thyroid carcinoma (FTC) is a well-differentiated malignancy that accounts
(C) 2020 The authors Published by Bioscientifica Ltd. Printed in Great Britain

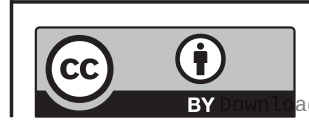

This work is licensed under a Creative Commons Attribution 4.0 International License. 
for about $10-15 \%$ of all thyroid cancers (AschebrookKilfoy et al. 2011). It shows a 5-year survival of about $90 \%$ but a 10-year survival around 80\% (James et al. 2016). FTCs are subclassified as minimally invasive (miFTC), encapsulated angioinvasive (eaiFTC) and widely invasive (wiFTC) depending on the histopathologic features such as capsular and/or vascular invasion as specified by World Health Organization (WHO) guidelines from 2017 (Lloyd et al. 2017). FTCs with an oxyphilic phenotype are classified as Hürthle cell carcinomas (HuCC), and these show a worse clinical outcome (Lloyd et al. 2017).

There are several well-established genetic driver events behind the development of follicular thyroid tumors. Somatic mutations in the RAS family are commonly found in both follicular thyroid adenomas (FTAs) and FTCs (HRAS, KRAS and NRAS) (Lemoine et al. 1989, Suarez et al. 1990, Esapa et al. 1999), showing a frequency of approximately 60\% in FTC (Fukahori et al. 2012). The PAX8/PPARG gene fusion is another well-established genetic event found in 30-60\% of FTCs (Kroll et al. 2000, Marques et al. 2002, Nikiforova et al. 2003). Activation of the PI3K/Akt pathway have also been observed in FTC (Hou et al. 2007), and recent studies have also identified mutations and aberrant methylation in the telomerase reverse transcriptase (TERT) promoter region, as well as TERT copy number gains and expression which have also been associated with a poor prognosis (Liu et al. 2014, Wang et al. 2014, Liu \& Xing 2016, Paulsson et al. 2018).

The mechanisms of tumorigenesis in a substantial subset of FTCs are still unknown, therefore recent studies have utilized next-generation sequencing in an attempt to identify additional genetic changes in FTC. In addition to known driver genes, DICER1 was found recurrently mutated in 7-10\% of FTCs (Yoo et al. 2016, Nicolson et al. 2018). The DICER1 gene, located on chromosome 14q32.13, is comprised of 27 exons (ENST00000343455.7) and encodes a highly conserved protein (DICER1 in Homo sapiens) that functions as an RNase III enzyme involved in the maturation of miRNA (Bernstein et al. 2001, Foulkes et al. 2014). In recent years there have been reports of DICER1 gene mutations in several endocrine malignancies, including thyroid cancer (Solarski et al. 2018). The somatic DICER1 gene mutations reported in PTC have been predicted to have a high impact on the function of the DICER1 protein (Cancer Genome Atlas Research Network 2014, Costa et al. 2015). Most of the reported somatic mutations are concentrated to the RNase IIIb region (exon 24 and 25), which is in contrast to the germline DICER1 gene mutations that are found spread out across the gene, resulting in a phenotype predisposed for tumours such as pleuropulmonary blastoma, SertoliLeydig cell tumour, multinodular goitre and thyroid cancer, collectively called DICER1 syndrome (Hill et al. 2009, Slade et al. 2011, Foulkes et al. 2014). These findings suggest that DICER1 alterations is an important factor for the development of both benign and malignant thyroid nodules. Moreover, a recent study of PTC clinical samples and cell lines proposed that the transcription factor GA binding protein (GABPA) regulates DICER1 transcriptionally (Yuan et al. 2019). We therefore aimed to establish the contribution of DICER1 dysregulation in follicular thyroid tumorigenesis and to examine the relationship between DICER1 and GABPA in a large clinical material as well as in established FTC cell lines.

\section{Materials and methods}

\section{Patient information and tumour specimen}

Informed consent was collected before the study was carried out and the study was approved by the Ethical Review Board (Etikprövningsmyndigheten, Stockholm). The samples were collected from the Karolinska University Hospital biobank and included patients operated at Karolinska University Hospital between the years 1986 to 2017. All cases were diagnosed by an endocrine pathologist and later re-classified by an additional independent endocrine pathologist according to the WHO 2017 guidelines (Lloyd et al. 2017). In total, the cohort included 168 patients diagnosed with either follicular thyroid adenoma (FTA) $(n=43)$, follicular tumour of uncertain malignant potential (FT-UMP) $(n=7)$, HuCC $(n=24)$ or FTC $(n=94)$. Non-neoplastic thyroid tissues used for endogenous control experiments included ten cases of normal thyroid tissue obtained from patients with benign thyroid or parathyroid disease and six cases of multinodular goitre. Normal thyroid tissue was also present adjacent to FTCs/HuCCs in subsets of the slides used for immunohistochemical analyses and used as internal references.

\section{Cell lines and culture conditions}

Human follicular thyroid carcinoma cell lines FTC-133 (derived from a lymph node metastasis) and FTC-238 (derived from a lung metastasis) (product numbers 94060901 and 94060902 respectively, Sigma) https://erc.bioscientifica.com https://doi.org/10.1530/ERC-19-0446
(C) 2020 The authors Published by Bioscientifica Ltd. Printed in Great Britain
This work is licensed under a Creative Commons Attribution 4.0 International License. ed from Bioscientifica.com at 04/26/2023 08:31:53AM 
were included in this study. The mutational landscape of both cell lines was recently published (Landa et al. 2019), and we confirmed the presence of a homozygous TERT promoter mutation c. $228 \mathrm{C}>\mathrm{T}(-124 \mathrm{C}>\mathrm{T})$ by Sanger sequencing in both cell lines (data not shown). The cell lines are identical to the source provided by the depositor based on an STR-PCR analysis. Cells were maintained in DMEM supplemented with 5\% foetal bovine serum (FBS) in culture dishes. Experiments were conducted after 12-15 passages, allowing a maximum of 15 passages.

\section{siRNA treatment, DICER1 and GABPA overexpression}

For GABPA and DICER1 silencing, $1 \times 10^{5}$ cells were transfected with 25 pmol siRNA. The GABPA siRNAs are entitled siGABPA\#1 and siGABPA\#2; both customized as described previously from Thermo Fisher Scientific (Yuan et al. 2019). For DICER1, the siRNAs were entitled siDICER1\#1 and siDICER1\#2 (siDICER1\#1 customized as previously described from Invitrogen (Yuan et al. 2019) and commercially available siDICER1\#2, product number \#6576, Cell Signaling Technology). In addition, a control siRNA (Sigma) was used. Cells were transfected with Lipofectamine 3000 (Thermo Fisher Scientific) according to the protocol provided by the manufacturer. Sequences for siRNAs are listed in Supplementary Table 1 (see section on supplementary materials given at the end of this article).

Plasmid (pCMV6entryHisDICER) for DICER1 overexpression was constructed based on pDESTmycDICER (Addgene, Cat\#19873). Restriction enzymes Not I, Sal I, and HindIII were used to digest pDESTmycDICER, and target backbone, pCMV6entry was treated with Not I and Sal I. Purified DICER1 ORF, as well as pCMV6entry, after electrophoresis were ligated by T4 DNA ligase. Sanger sequencing confirmed the pCMV6entryHisDICER construction. All enzymes were purchased from New England Biolabs, and E. coli DH5 $\alpha$ were used to amplify the plasmid. For DICER 1 overexpression, $8 \times 10^{4}$ cells were grown with $70-80 \%$ confluence on 6-well plates and then transfected with either $2 \mu \mathrm{g} /$ well pCMV6-entry DICER expression plasmid or empty vector using Lipofectamine 3000 (Thermo Fisher Scientific) according to the protocol provided by the manufacturer. The construct was validated by Sanger sequencing at the KIGene core facility.

For the GABPA overexpression, the plasmid construct has been previously described in detail, and the methodology followed the same principles as for DICER1, except for the usage of Lipofectamine LTX instead of Lipofectamine 3000 as a transfection agent (Yuan et al. 2019).

\section{Sanger sequencing}

In total, 61 FTCs, 15 HuCCs, 43 FTAs and 7 FT-UMPs were analysed for the DICER1 hot spot mutations in codon 1705, 1709, 1810, 1813 and 1814 using Sanger sequencing with primers specified in Supplementary Table 1. The tumours were also analysed for the mutations reported in the wholeexome sequencing study (Nicolson et al. 2018), codons 290 and 304, with primers specified in Supplementary Table 1. The chromatograms were aligned to reference sequence and manually analysed using Genome Compiler (Twist Bioscience, San Francisco, CA, USA) and CodonCode Aligner (CodonCode Corporation, Centerville, MA, USA).

\section{Copy number alterations}

Copy number $(\mathrm{CN})$ alterations of the DICER1 gene locus was assessed in 48 FTCs and 12 HuCCs. The samples were analysed using the TaqMan assays (Applied Biosystems), Hs02002254_cn for DICER1 and TaqMan Copy number reference assay $R N a s e P$ as endogenous control. The $\mathrm{CN}$ was calculated using CopyCaller v.2.1 (Applied Biosystems). Six cases of multinodular goitre were included as calibrator samples in every run, and additionally, three normal thyroid samples were also used as diploid controls. CN gain was defined as three or more copies and $\mathrm{CN}$ loss as one copy or less.

\section{mRNA expression analyses}

Total RNA from human thyroid tissue and cell lines was extracted with mirVana RNA Isolation kit (Applied Biosystems) and cDNA synthesized using High-Capacity cDNA Reverse Transcription Kit (Applied Biosystems). Quantitative real-time PCR (qRT-PCR) was performed in FTC-238 cells, 42 FTAs, 49 FTCs and 13 HuCCs. Ten non-cancerous thyroid tissue samples were used as references. DICER1 and GABPA mRNA expression levels and endogenous control $\beta$-actin were investigated using SYBR Green with ABI 7900HT real-time PCR system (Applied Biosystems). Samples were run in triplicates, and the relative expression levels of GABPA and DICER1 were quantified by normalization to the housekeeping gene $\beta$-actin and calculations based on $2^{-\Delta \mathrm{Ct}}$ in tissues and $2^{-\Delta \Delta \mathrm{Ct}}$ in cell lines. Primer sequences are listed in Supplementary Table 1.

\section{miRNA expression}

Total RNA was extracted from cell lines using the mirVana RNA Isolation kit (Applied Biosystems) and cDNA

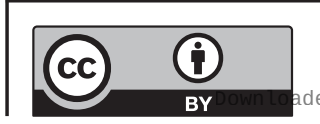

This work is licensed under a Creative Commons Attribution 4.0 International License. 
was synthesized using MicroRNA cDNA Synthesis kit (Applied Biosystems) with assay specific TaqMan primers, miR-34a-5p (hsa-miR-34a, 000425), miR-199a (hsa-miR-199a, 000498) and the control assay RNU6B (001093) (Applied Biosystems). Samples were run in StepOnePlus Real-Time PCR System (Applied Biosystems) in triplicates with assay specific TaqMan primers stated previously and expression levels were calculated using the $2^{-\Delta \Delta \mathrm{Ct}}$.

\section{Immunohistochemistry}

In total, 44 cases of FTCs and seven cases of HuCCs were subject to immunohistochemical staining. The tissue slides included corresponding normal thyroid tissue for 40 cases. All cases were formalin-fixed paraffin-embedded, cut into $4 \mu \mathrm{m}$ thick sections and stained using the Envision+ Dual Link System-HRP (DAB+) (DAKO). The tissue slides were incubated with the Anti-Dicer MAB (ab14601, Abcam, diluted 1:100) for $30 \mathrm{~min}$ at room temperature before proceeding with the DAKO staining according to the manufacturer's instructions. The slides were counter-stained with haematoxylin for $5 \mathrm{~min}$ and then mounted. The stained slides were subsequently evaluated by an experienced endocrine pathologist and scored as either 'negative' (completely devoid of immunoreactivity), 'weak/focal' (weak staining in subsets of cells), 'intermediate' (diffuse staining of moderate intensity) or 'strong' (diffuse staining of strong intensity).

\section{Immunoblot}

Protein pellets were extracted with NP40 lysis buffer and $30 \mu \mathrm{g}$ of protein was used. The membranes were incubated with the following primary antibodies: Anti-NRF2A/ GABPA (rabbit polyclonal antibody ABE1047, Millipore, at 1:1000 dilution) and anti-DICER (rabbit MAB D38E7, Cat\# 5362, Cell Signaling Technology, at 1:1000 dilution in 5\% non-fat milk). Anti- $\beta$-actin (mouse MAB from Sigma, clone A1978) or GAPDH (rabbit MAB, clone 14C10, Cell Signaling Technology) signal served as loading controls.

\section{Chromatin immunoprecipitation}

Chromatin immunoprecipitation (ChIP) assay was performed using SimpleChIP kit (\#9005, Cell Signaling Technology). FTC-238 cells were cross-linked in 1\% formaldehyde-containing medium and then sonicated to make soluble chromatin. Anti-GABPA and antiIgG were used to precipitate DNA fragments bound by GABPA. The reverse-cross-linked DNA was used for PCR amplification and subsequent sequencing. The GABPA predicted binding sites of the DICER1 promoter have been previously published (Yuan et al. 2019). The PCR primers for the DICER1 promoter are listed in Supplementary Table 1 , and a detailed ChIP protocol is available on request.

\section{Cell proliferation analyses}

Approximately $8 \times 10^{4}$ FTC-238 cells were seeded into 6-well plates, treated with DICER1 depletion and DICER1 overexpression, respectively, stained with Incucyte Nuclight Rapid Red Reagent for cell labelling (Sartorius, Göttingen, Germany) and placed in an incubation chamber maintained at $37^{\circ} \mathrm{C}$. Real-time proliferation of FTC-238 cells was photographed and analysed by the IncuCyte S3 Live Cell Imaging and Analysis System (Essen Bioscience, Ann Arbor, MI, USA) through quantitatively detecting alive cells up to $72 \mathrm{~h}$ from start. The changes in living cell number represent the cell proliferation.

\section{Trypan blue exclusion assay}

Approximately $8 \times 10^{4}$ FTC-238 cells were seeded into 6-well plates, treated with control and DICER1 depletion via siRNA, respectively, then cells were collected at $24 \mathrm{~h}$, $48 \mathrm{~h}$ and $72 \mathrm{~h}$, stained with trypan blue and counted with a TC10 Automated Cell Counter (BioRad) for cell growth.

\section{Analysis of apoptosis by fluorescence-activated cell sorting (FACS)}

GABPA-depleted FTC-238 cells and controls were analysed by fluorescence-activated cell sorting (FACS). Treated and untreated FTC-238 cells were stained with Annexin-V conjugated to fluorescein isothiocyanate (FITC) and propidium iodide (PI) (BioLegend, San Diego, CA, USA) according to the manufacturer's instructions. Briefly, cells were suspended in $400 \mu \mathrm{L}$ of Annexin V binding buffer and incubated with $5 \mu \mathrm{L}$ of FITC Annexin-V and $10 \mu \mathrm{L}$ of PI for $15 \mathrm{~min}$ at room temperature in darkness. After staining, the cells were analysed in a flow cytometer using 488-nm excitation and a 525-nm band pass filter for FITC and a 620-nm filter for PI detection. The percentage of cells undergoing apoptosis were determined by dual-colour analysis. Results were obtained from three independent experiments.

\section{Statistical analyses}

Categorical and binary variables were presented as number ( $n$ ) and proportion (\%) of cases, respectively.

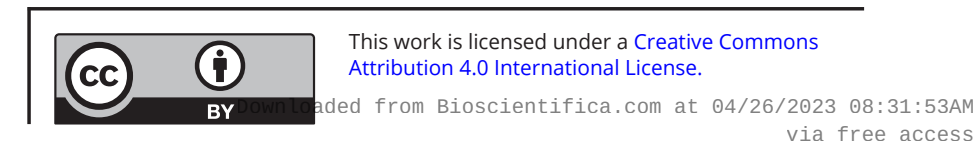


Chi-square and Fisher's exact tests were used to compare categorical variable differences. Kaplan-Meier was used to plot overall survival (the percentage of patients in our study who are still alive for a certain period of time after they were diagnosed with FTC/HuCC), disease-free survival (the length of time after primary treatment for FTC/HuCC without known recurrence) and/or disease-specific survival (the percentage of people in our study who have not died from FTC/HuCC in a defined period of time) in cancer patients with low and high DICER1 mRNA expression (first and fourth quartile, respectively) and log-rank test was used to calculate statistical significance. The differences in DICER1 and GABPA mRNA levels between tumours and normal thyroid tissues were analysed using the MannWhitney $U$ test. Comparison of expression in DICER1 and GABPA mRNA between control and treated group in FTC cell lines was analysed using Student's $t$-test. Comparison of cell proliferation between control and treated group in FTC cell lines was analysed using Student's $t$-test and two-way ANOVA analysis. The Pearson and Spearman correlation tests were used to calculate the correlation between continuous variables. Calculations and graphs were prepared in SPSS version 25 (IBM SPSS Statistics, IBM) and GraphPad Prism version 8 (GraphPad Software). $P$ values $\leq 0.05$ were considered statistically significant.

\section{Results}

\section{Patient characteristics}

The clinical characteristics of the patients included in the study are summarized in Table 1. A total number of 168 patients were included in the study. The mean age at surgery was 51, 49, 54 and 59 years for FTA, FT-UMP, FTC and HuCC, respectively. The FTA and FT-UMP groups included 15 and four Hürthle cell tumours, respectively, whereas the HuCCs were separated from the FTC group. There was no relapse in the FTA group but one relapse in the FT-UMP group. The FTC group included eight patients

Table 1 Clinical characteristics of included cases.

\begin{tabular}{l}
\hline \\
Parameter \\
\hline Mean age at diagnosis, \\
years (min-max) \\
Female patients, $n$ (\%) \\
Mean tumor diameter, \\
mm (min-max) \\
WHO 2017 subtype \\
Minimally invasive \\
(miFTC), $n$ (\%) \\
Encapsulated \\
angioinvasive \\
(eai FTC), $n$ (\%) \\
Widely invasive \\
(wiFTC), $n$ (\%) \\
T category \\
pT1 \\
pT2 \\
pT3 \\
pT4 \\
Hürthle cell, $n$ (\%) \\
Extrathyroidal \\
growth, $n(\%)$ \\
Mean Follow-up time, \\
months (min-max) \\
Outcome \\
AWOD, $n(\%)$ \\
AWD, $n(\%)$ \\
DOD, $n(\%)$ \\
DOOC, $n(\%)$ \\
\hline
\end{tabular}

\begin{tabular}{|c|c|}
\hline \multicolumn{2}{|c|}{ FTA $(n=43)$} \\
\hline Observation & $\begin{array}{l}\text { No of } \\
\text { inf. }(n)\end{array}$ \\
\hline $51(25-87)$ & 43 \\
\hline $\begin{array}{l}31(72.1) \\
32(14-60)\end{array}$ & $\begin{array}{l}43 \\
43\end{array}$ \\
\hline - & \\
\hline - & \\
\hline - & \\
\hline - & \\
\hline - & \\
\hline - & \\
\hline - & \\
\hline 15 (34.9) & 43 \\
\hline- & \\
\hline $70(23-140)$ & 43 \\
\hline & 43 \\
\hline $40(93)$ & \\
\hline $0(0)$ & \\
\hline $0(0)$ & \\
\hline $3(7)$ & \\
\hline
\end{tabular}

\begin{tabular}{cc}
\hline \multicolumn{2}{c}{ FT-UMP $(n=7)$} \\
\cline { 1 - 1 } \begin{tabular}{c} 
Observation \\
\cline { 1 - 1 } $49(30-75)$
\end{tabular} & $\begin{array}{c}\text { No of } \\
\text { inf. }(n)\end{array}$ \\
$7(100)$ & 7 \\
$33(15-70)$ & 7
\end{tabular}

\begin{tabular}{lc}
\hline \multicolumn{2}{c}{ FTC $(n=94)$} \\
\cline { 1 - 1 } $\begin{array}{l}\text { Observation } \\
\text { S4 (10-91) }\end{array}$ & $\begin{array}{l}\text { No of } \\
\text { inf. }(n)\end{array}$ \\
\hline 64 & \\
$40(63.8)$ & 94 \\
$43(15-100)$ & 90
\end{tabular}

\begin{tabular}{|c|c|}
\hline \multicolumn{2}{|c|}{ HuCC $(n=24)$} \\
\hline Observation & $\begin{array}{l}\text { No of } \\
\text { inf. }(n)\end{array}$ \\
\hline $59(29-80)$ & 24 \\
\hline $16(66.7)$ & 24 \\
\hline $43(20-80)$ & 24 \\
\hline & 24 \\
\hline $9(37.5)^{a}$ & \\
\hline $5(20.8)^{a}$ & \\
\hline
\end{tabular}

aSubtypes as defined for FTCs. No such subtyping is recommended for HuCCs according the 2017 WHO but are listed here for clarity. AWD, alive with disease; AWOD, alive without disease; DOD, dead of disease; DOOC, dead of other cause; FTA, follicular thyroid adenoma; FTC, follicular thyroid carcinoma; FT-UMP, follicular tumour of uncertain malignant potential; HuCC, Hürthle cell carcinoma; No of inf., Number of informative cases.

https://erc.bioscientifica.com https://doi.org/10.1530/ERC-19-0446 (c) 2020 The authors Published by Bioscientifica Ltd. Printed in Great Britain

$13(14.0) \quad 5(20.8)^{a}$

$40(43.0)$

$10(41.7)^{\mathrm{a}}$

$11(12.1)$

$28(30.8)$

$52(57.1)$

$0(0)$

$4(57.1)$

7

$0(0)$

7 (7.6)

98 (7-389)

7

5 (71.4)

1 (14.3)

0 (0)

1 (14.3)
$64(68.1)$

$8(8.5)$

$11(11.7)$

$11(11.7)$
91

94

24

$2(8.3)$

8 (33.3)

$13(54.2)$

$1(4.2)$

$24(100)$

4 (16.7)

24

24

$94 \quad 95(13-328) \quad 24$

94

$15(62.5)$

$0(0.0)$

7 (29.2)

$2(8.3)$ 
with metastatic disease, and 11 patients that died from the disease but none with metastatic disease. The HuCC group included seven patients who died from the disease but no additional patients with metastatic disease.

\section{DICER1 mutations in follicular thyroid tumours}

To determine the occurrence of DICER1 mutations in follicular thyroid tumours, a total number of 126 tumours were sequenced for mutations in regions previously reported in thyroid cancer. The results are illustrated in Supplementary Fig. 1. Across the cohort, three mutations in two cases were observed. The first case showed a missense mutation at position c.5428G $>\mathrm{T}$ (p.D1810Y) and, in addition, a nonsense mutation at position c.911C >A (p.S304X). The patient was a 14-year-old girl diagnosed with miFTC, and these mutations have been previously published for this patient and verified as somatic (Nicolson et al. 2018). She exhibited no family history of the DICER1 syndrome. The second patient with a DICER1 mutation showed a missense mutation at position c.5437G>C (p.E1813Q). This patient was a 10-year-old girl diagnosed with a wiFTC. No constitutional DNA was available for testing whether this variant was constitutional or somatic in origin; however, no family history indicative of the DICER1 syndrome was evident.

\section{DICER1 copy number alterations in FTC/HuCC}

The gene copy number of the DICER1 locus was determined in 48 FTCs and 12 HuCCs, six multinodular goitre samples and three normal thyroids. Two of the 48 FTCs displayed three copies of the DICER1 gene locus (CN gain) and one HuCC showed one copy (CN loss) (data not shown). No copy number aberrations were found in the non-neoplastic group $(n=9)$ of normal thyroid and multinodular goitre samples. The HuCC case with $\mathrm{CN}$ loss displayed low levels of DICER1 mRNA expression.

\section{Down-regulation of DICER1 mRNA and protein expression}

The mRNA expression of DICER1 was determined in 49 FTCs, 13 HuCCs, 42 FTAs and ten normal thyroid tissues. FTCs and HuCCs displayed lower levels of DICER1 mRNA compared to normal thyroid tissue (Fig. 1A, $P=0.0079$ and $P<0.001$ respectively). DICER 1 mRNA expression levels were lower in HuCCs as compared to FTCs (Fig. $1 \mathrm{~A}, P<0.001)$. The DICER1 mRNA expression levels were significantly lower also in FTA compared to normal tissue
(Fig. $1 \mathrm{~B}, P=0.0192$ ). To visualize the DICER1 expression pattern, a total of 51 cancerous samples (44 FTC, seven HuCC) and 40 matched normal thyroid samples were stained for DICER1 and graded in a semi-quantitative manner. In a majority of cases, a cytoplasmic staining was observed. Lower DICER1 immunoreactivity in cancerous tissue compared to normal thyroid tissue was observed $(P<0.001)$, as calculated with Mann-Whitney $U$ test in a semi-quantitative method. Figure 2 shows two representative cases, where the expression in the central parts of the tumours is lost and the corresponding normal thyroid tissue shows positive cytoplasmic staining.

\section{GABPA mRNA expression is correlated to DICER1 mRNA expression in FTC/HuCC}

Given earlier observations of DICER1 and GABPA correlation in PTC, we explored the relationship between these in FTC/HuCC. GABPA mRNA expression was slightly lower in normal thyroid tissue compared to FTC/ HuCC (Fig. 1C, $P=0.0283$ ). Based on expression data in 39 FTCs and nine HuCCs, the DICER1 and GABPA mRNA expression showed a positive correlation (Fig. 1D).

\section{DICER1 expression is reduced after GABPA silencing in FTC-238}

As our clinical samples showed a positive correlation between GABPA mRNA expression and DICER1 mRNA expression in thyroid cancer tissues, we sought to explore the relationship between these in FTC cell lines. GABPA was knocked down using specific siRNAs and subsequent DICER1 expression was assessed in FTC cell lines. The efficiency of inhibition of GABPA expression in siRNA treated cells was verified using qRT-PCR and Western blot. Successful inhibition was achieved in FTC-238 and subsequent experiments were performed in this cell line. As shown in Fig. 3A, B and C, GABPA and DICER1 mRNA expression and protein expression decreased significantly in GABPA depleted FTC-238 cells.

\section{GABPA overexpression induces augmented DICER1 protein expression}

By transfecting FTC-238 cells with a GABPA expression plasmid, increased DICER1 protein expression was evident by Western blot analyses (Supplementary Fig. 2). The results were conducted using two different plasmid concentrations, and visible up-regulation of DICER1 was evident in both experiments.

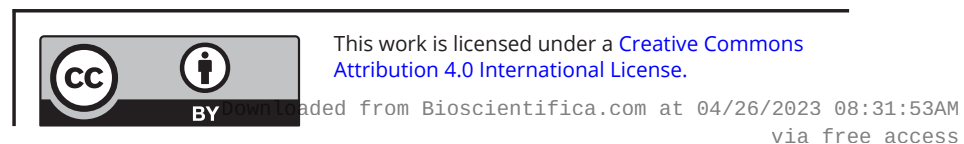



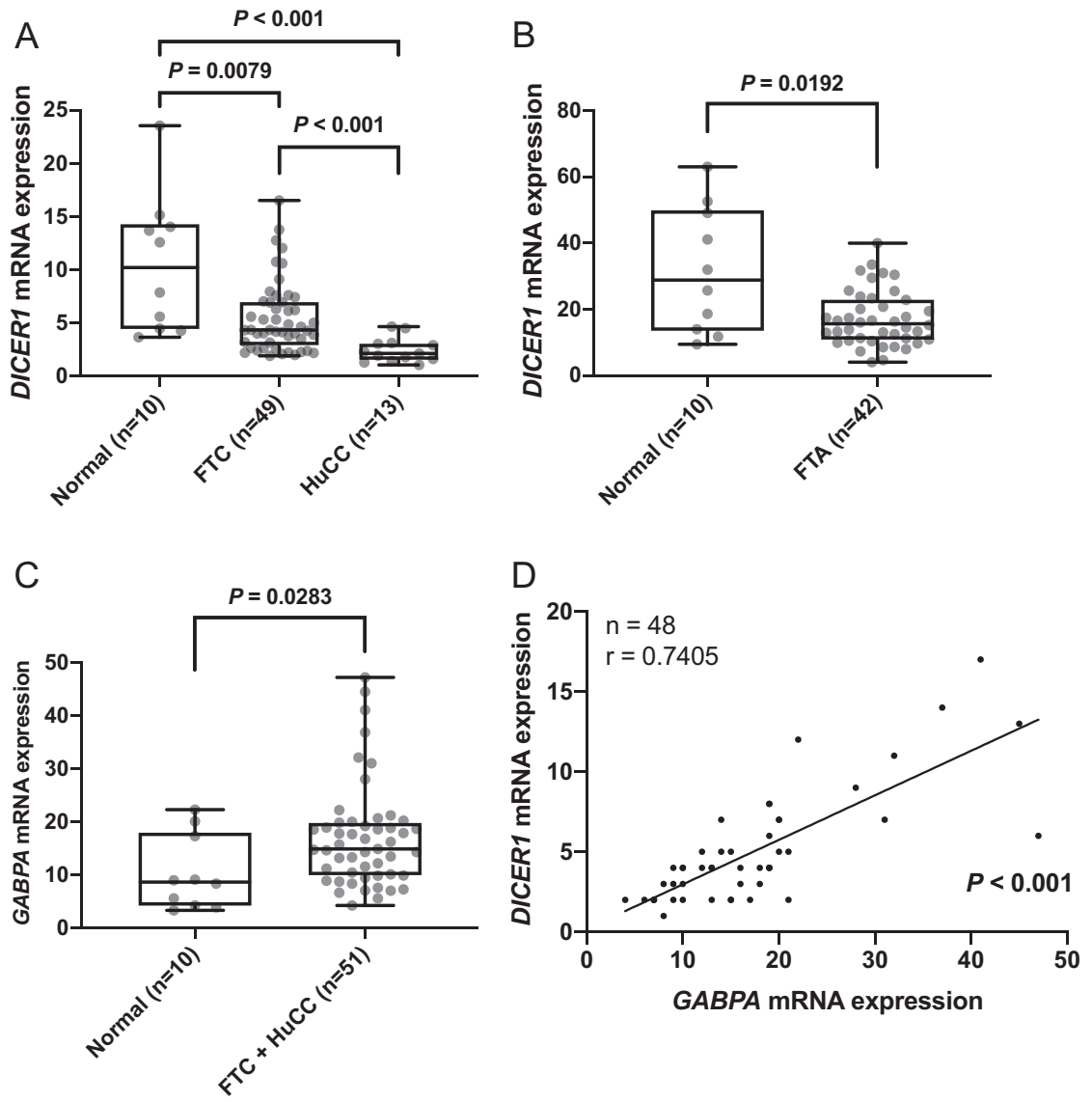
Figure 1
Relative DICER1 and GABPA mRNA expression and their correlation in follicular thyroid carcinomas (FTC), Hürthle cell carcinomas (HuCC) and follicular thyroid adenomas (FTA). (A) DICER1 mRNA expression in normal thyroid tissue vs FTC and HuCC. (B) DICER1 mRNA expression in normal thyroid samples vs FTAs. (C) GABPA mRNA expression in normal thyroid tissue vs FTC/HuCC. (D) Correlation of DICER1 mRNA expression and GABPA mRNA expression in FTC/HuCC. $P$ values were calculated with Mann-Whitney $U$ test, Spearman's and Pearson correlation. Significant $P$ values are in bold.

\section{GABPA interacts with DICER1 through binding the DICER1 promoter}

To further explore the interaction between GABPA and DICER1, a ChIP was performed in FTC-238 cells. After pulling down the DNA-protein complex with anti-GABPA antibody, a selected area of the DICER1 promoter was amplified using primers specific to the DICER1 promoter region and sequenced (Fig. 4A and B), showing a physical interaction between the transcription factor GABPA and DICER1.

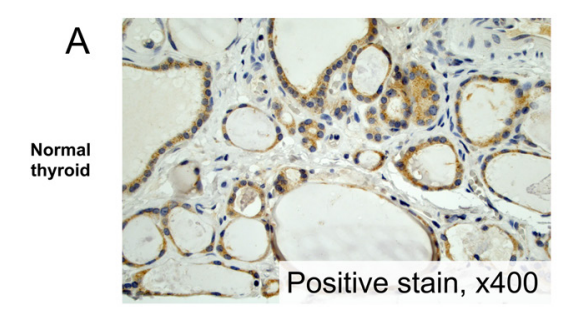

B
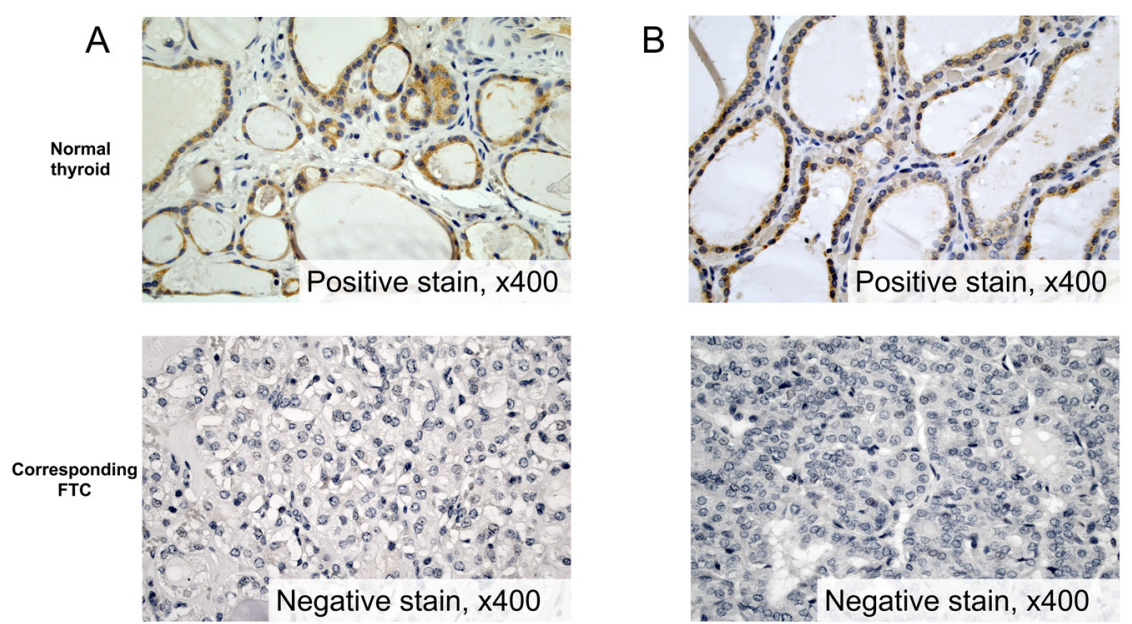

C

\begin{tabular}{lrrrrr}
\hline & Negative (0) & Weak/Focal (1) & Intermediate (2) & Strong (3) & Total \\
Normal & 0 & 12 & 26 & 2 & 40 \\
FTCs/HuCCs & 3 & 36 & 6 & 6 & 51 \\
\hline
\end{tabular}

Figure 2

Representative images of the DICER1 immunohistochemistry staining and summary of the staining results. ( $A$ and $B$ ) The staining of DICER1 in two cases of FTC shows positive staining of the corresponding normal tissue and negative staining in the central parts of the tumour. The tumour tissue, in general, showed weaker DICER1 immunoreactivity compared to the corresponding normal thyroid tissue. Magnification $\times 400$. (C) Summarized results from the immunohistochemical scoring of normal thyroid tissue, follicular thyroid carcinomas (FTC) and Hürthle cell carcinomas (HuCC). A full colour version of this figure is available at https://doi. org/10.1530/ERC-19-0446. https://erc.bioscientifica.com https://doi.org/10.1530/ERC-19-0446 Printed in Great Britain
This work is licensed under a Creative Commons Attribution 4.0 International License. 

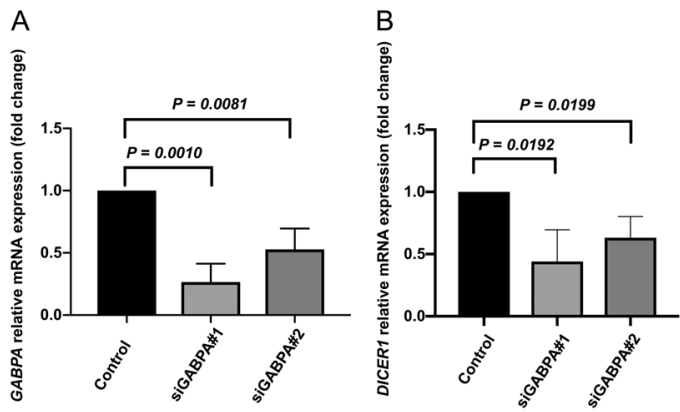

C

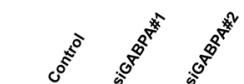

GABPA

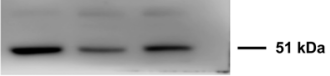

DICER

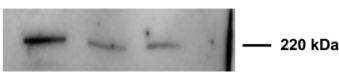

GAPDH

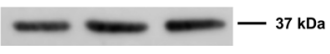

Figure 3

GABPA knock down in FTC-238 cell line. (A) GABPA

mRNA expression in the knock down cells (siGABPA\#1 and siGABPA\#2) is significantly reduced compared to control cells. (B) DICER1 mRNA expression in the knock down cells (siGABPA\#1 and siGABPA\#2) is significantly reduced compared to control cells. (C) Confirmation of reduced levels of GABPA and DICER1 after GABPA knock down. Estimated protein sizes are indicated to the right in kilodaltons $(\mathrm{kDa}) . P$ values were calculated with Student's $t$-test. Significant $P$ values are in bold.

\section{DICER1 silencing and overexpression in the FTC-238 cell line alters the proliferation rate}

To explore the proliferative effects of DICER1, FTC-238 cells were treated with DICER1 siRNA and an DICER1 overexpression vector, respectively. Cell proliferation was assessed at different time points in real time (Fig. 5A, B, $\mathrm{C}, \mathrm{D}$ and $\mathrm{E})$. Increased cell proliferation was observed in DICER1 siRNA treated cells compared to the control (Fig. $5 \mathrm{~B})$, and likewise, decreased proliferation was evident in DICER 1 overexpression experiments (Fig. 5C and D). The real-time growth pattern of FTC-238 cells at different time points was also visualized (Fig. 5E). DICER1 knockdown and overexpression was confirmed with Western blot (Fig. 5F).

\section{Cell viability is increased upon DICER1 depletion visualized by Trypan blue assay}

Analyses of DICER1 depleted FTC-238 cells collected at $24 \mathrm{~h}, 48 \mathrm{~h}$ and $72 \mathrm{~h}$ revealed an increase in viable FTC-238 cells at all three time points observed (Supplementary Fig. 3).

\section{Analysis of apoptosis by fluorescence-activated cell sorting (FACS)}

To study an eventual GABPA mediated effect on apoptosis in FTC-238 cells, GABPA depleted cells were analysed using fluorescence-activated cell sorting (FACS). As illustrated in Supplementary Fig. 4, there were no evident differences in the number of cells in early or late stages of apoptosis between control cells and GABPA knocked-down cells.

\section{miR-34a-5p is dysregulated after silencing of GABPA and DICER1}

To evaluate the consequences of DICER1 down-regulation on the miRNA machinery, the expression for two selected miRNAs was assessed based on previous reports of dysregulation (Rossing et al. 2012, Mancikova et al. 2015). The miR-199a-5p repeatedly did not show any expression in control or siRNA treated cells (data not shown). In contrast, $m i R-34 a-5 p$ was down-regulated in both DICER1 knock-down cells (Fig. 6A) and GABPA knock-down cells (Fig. 6B). We also employed the mIRDB database (http:// mirdb.org) to mine for predictive targets of $m i R-34 a-5 p$.

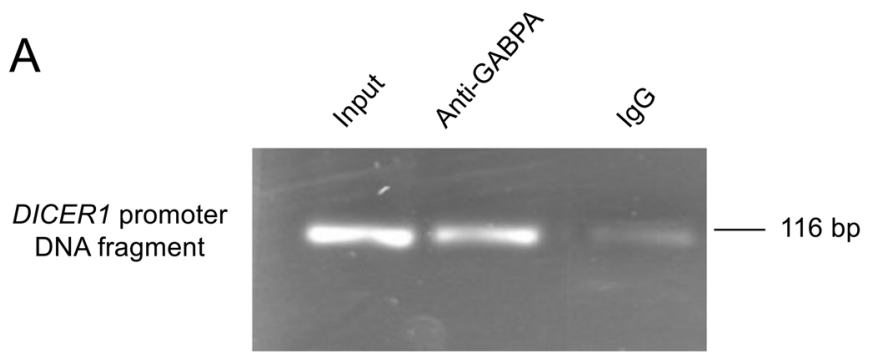

B

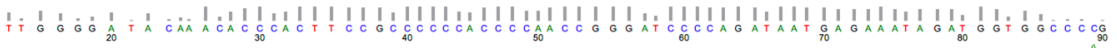

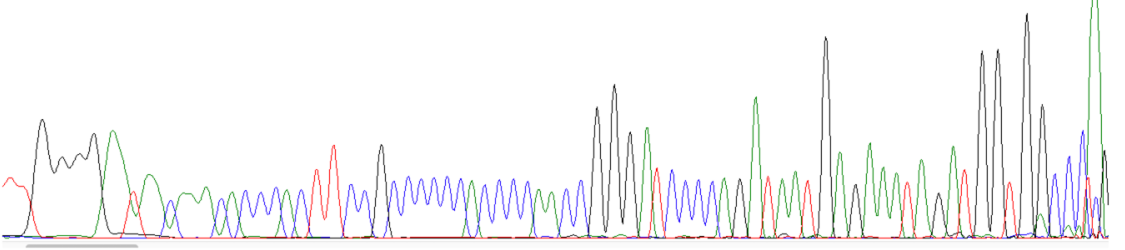

\section{Figure 4}

Chromatin immunoprecipitation assay of the binding of GABPA to the DICER1 promoter. (A) Gel electrophoresis showing DNA bands from DICER1 promoter PCR product. Lane 1 shows band from $2 \%$ input DNA, lane 2 shows band from pulled down DNA using GABPA antibody and lane 3 shows PCR product from cross-linked chromatin DNA incubated with normal rabbit IgG. (B) Chromatogram from the GABPA antibody pulled down DNA and subsequent amplification and sequencing of the DICER1 promoter using the reverse primer as sequencing primer. The sequence was blasted with a $100 \%$ match in the DICER1 promoter. A full colour version of this figure is available at https://doi.org/10.1530/ ERC-19-0446. https://erc.bioscientifica.com https://doi.org/10.1530/ERC-19-0446 Printed in Great Britain
This work is licensed under a Creative Commons Attribution 4.0 International License. 


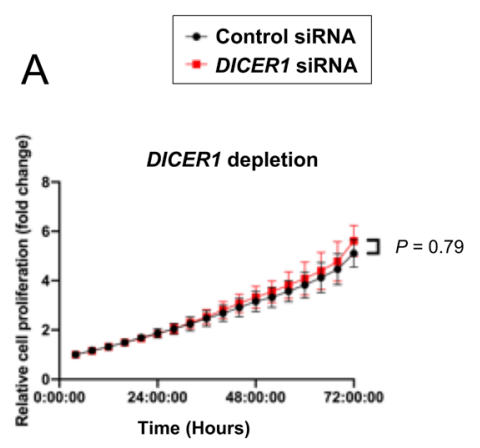

E
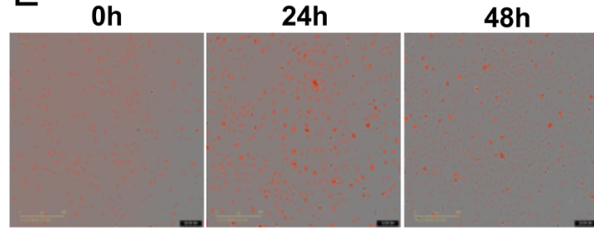

$8 \mathrm{~h}$

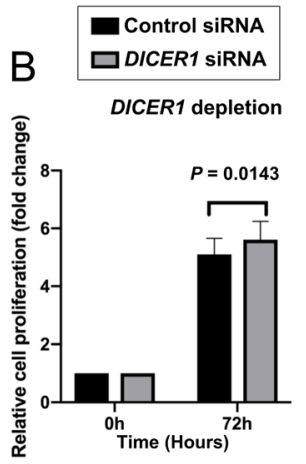

C
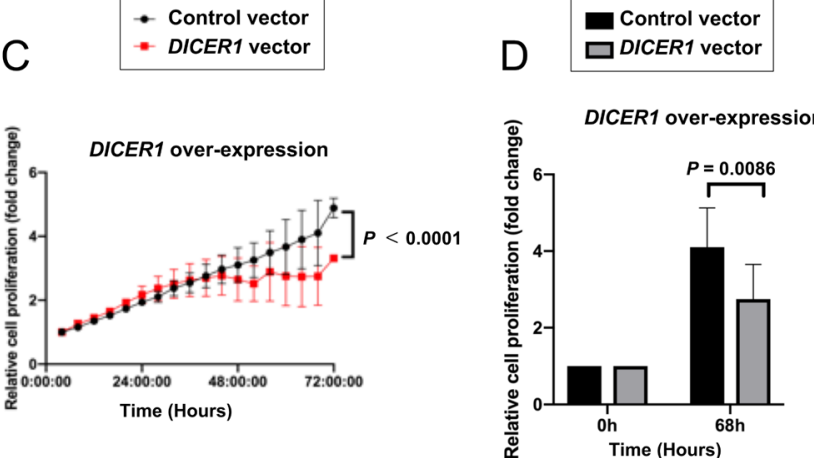

Control siRNA

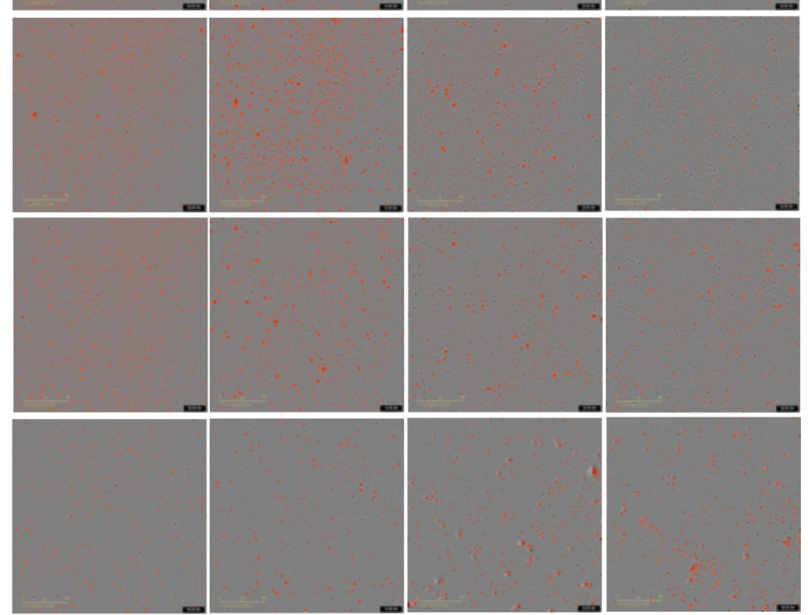

DICER1 SIRNA

Control vector

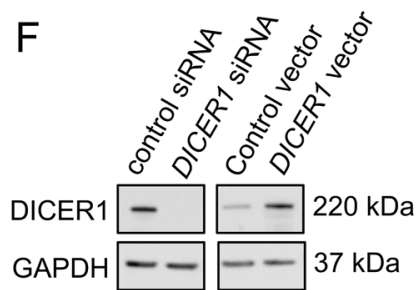

Figure 5

FTC-238 cell proliferation was assessed by monitoring alive cells in real time (Incucyte). Cell proliferation increased after DICER1 depletion using SIDICER1\#1 ( $A$ and B) and decreased in the DICER1 overexpression experiments ( $C$ and D). Difference in time and effect factors was analysed by two-way ANOVA. (B and D) Shows the relative increase and decrease in cell proliferation of FTC-238 cells at the starting and end points, respectively. Cell proliferation was calculated based on the cell number counting from three independent cell experiments, and relative cell proliferation was presented by comparing to cell numbers at the starting point. Date shown are the mean \pm S.D. $(n=3)$. Images in E represent the FTC-238 cells growth pattern at different time points, where the red signal indicates the stained cell nuclei. As shown in F, DICER1 depletion and overexpression experiments were confirmed by Western blot. Estimated protein sizes are indicated to the right. A full colour version of this figure is available at https://doi.org/10.1530/ ERC-19-0446.

A total of 899 potential targets were listed, of which we list the top 20 candidates in Supplementary Table 2.

\section{Clinical outcome in low DICER1 expressing cases}

Overall survival, disease-free survival and disease-specific survival were not significantly lower for low DICER1 expressing patients (Fig. 7A, B and C). However, as observed in Fig. 1A, the DICER1 mRNA expression was lower in HuCC, as was the disease-specific survival (Fig. 7D, $P=0.0123)$.

\section{Age-dependent associations to DICER1 expression}

The few DICER1 mutations reported here occurred in young patients. Therefore, we evaluated the differences in DICER1 mRNA expression between the groups. Higher DICER1 mRNA expression was observed in patients younger than 25 years, an arbitrary cut-off selected by the authors (Fig. 8A). The disease-free survival in older patients seems as expected to be shorter (Fig. 8B). The correlation between DICER1 mRNA expression and GABPA mRNA expression was also observed in both age groups (Fig. 8C and D). 
A

miR-34a-5p in DICER1 siRNAFTC-238 cells

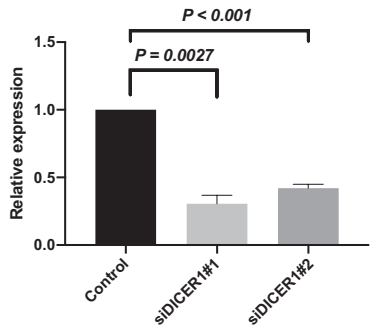

miR-34a-5p in GABPA siRNA FTC-238 cells

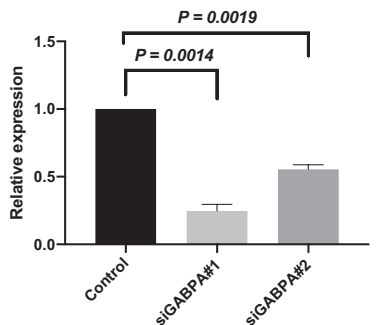

Figure 6

miRNA expression after GABPA and DICER1 knock-down cells respectively. (A) miR-34a-5p expression in DICER1 knock-down FTC-238 cells is reduced (B) miR-34a-5p expression in GABPA knock-down FTC-238 cells is also reduced.

\section{Discussion}

In this study, we aimed to explore the effects of dysregulated DICER 1 in FTC and its interactions with the transcription factor $G A B P A$ based on recent findings in thyroid cancers (Yoo et al. 2016, Nicolson et al. 2018, Yuan et al. 2019). In our cohort of thyroid tumours, mutations in commonly affected regions of the DICER1 gene seem to be a rare event. Interestingly, the few reported mutations in our cohort occurred in very young FTC patients, a 10- and 14-year-old female patient, respectively. Both showed missense mutations and DICER1 mRNA expression in the top 25 percentile. Unfortunately, no constitutional DNA was available for testing of the 10 -year-old patient, to determine the somatic or constitutional status of the mutation. The 14-year-old patient displayed two somatic mutations which were both present in heterozygous state as previously reported (Nicolson et al. 2018); however, no allelic separation was performed, and we cannot ascertain whether these mutations occurred in cis or in trans. Nevertheless, as both patients displayed missense mutations in the catalytic RNAse IIIb domain of DICER1 in addition to the additional stop mutation found in one of the patients, the mutations are expected to be of impact as they might alter the function of the DICER1 protein. Overall, these results demonstrate that paediatric patients with thyroid cancer, in general, could mandate specific clinical consideration given their potential associations to genetic alterations not usually found in adult thyroid cancer.

We also searched the Cancer Genome Atlas (TCGA) database for DICER1 mutations in follicular variant PTC (FV-PTC) patients from the cBio Cancer Genomics Portal. As FV-PTCs regularly display RAS family mutations and thereby bear some genetic similarities to follicular thyroid tumors, this was the most appropriate comparison as no bona fide FTC samples are displayed in the TCGA dataset. In the TCGA FV-PTC data set, one mutation in 107 cases has been reported, a missense p.R1906S mutation occurring in a 20-year-old female patient (TCGA-EM-A2CT). Thus, DICER1 mutations seems to be rare, but possibly aggregating in young and FV-PTC FTC patients $(2 / 11 ; 18 \%$ in our cohort). Intriguingly, DICER1 mutations have just recently been reported in macrofollicular variants of FTCs as well as in poorly differentiated thyroid cancer specimen occurring in younger patients (Bongiovanni et al. 2020, Chernock et al. 2020).

We observed DICER1 mRNA down-regulation in FTCs/HuCCs as well as in FTAs, and the results were
A Overall survival DICER1 mRNA expression

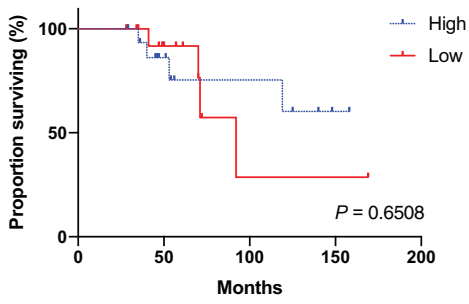

C

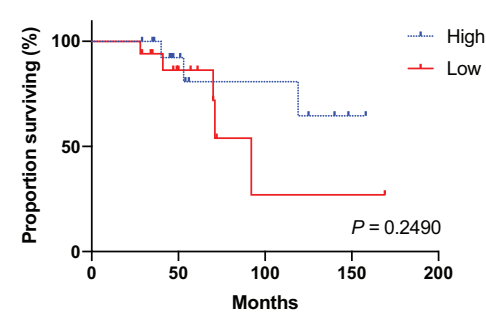

$B$

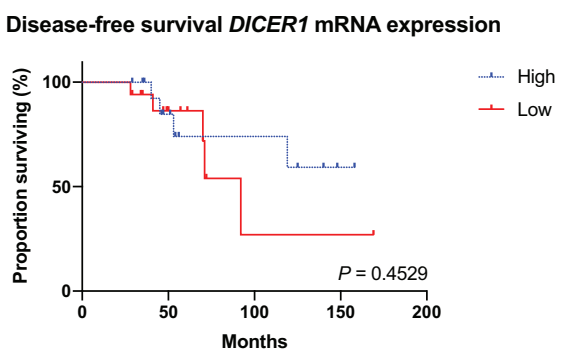

D DSS FTC vs HuCC

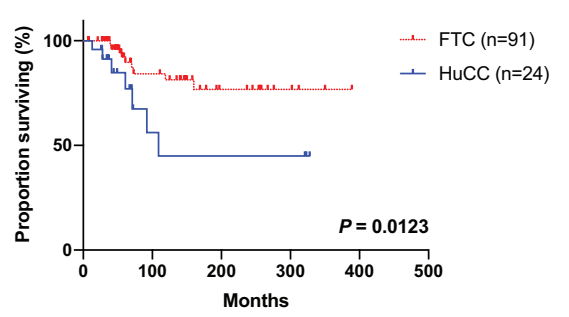

\section{Figure 7}

Kaplan-Meier survival curves in follicular thyroid carcinoma (FTC) and Hürthle cell carcinoma (HuCC) patients. (A) The overall survival in low vs high DICER1 expression. (B) The disease-free survival in low vs high DICER1 expression. (C) The disease-specific survival (DSS) in low vs high DICER1 expression. (D) DSS in FTC vs HuCC. $P$ values were calculated using the Log-rank test. Significant $P$ values are in bold. A full colour version of this figure is available at https://doi. org/10.1530/ERC-19-0446. https://erc.bioscientifica.com https://doi.org/10.1530/ERC-19-0446 (c) 2020 The authors Published by Bioscientifica Ltd. Printed in Great Britain
This work is licensed under a Creative Commons Attribution 4.0 International License. 
A

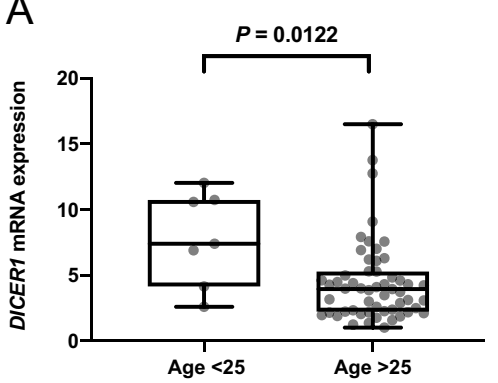

C

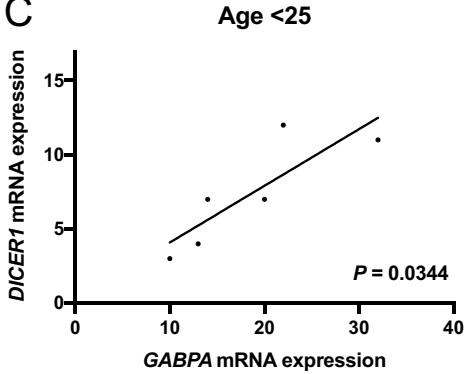

B Disease-free survival Age $<25$ vs $>25$
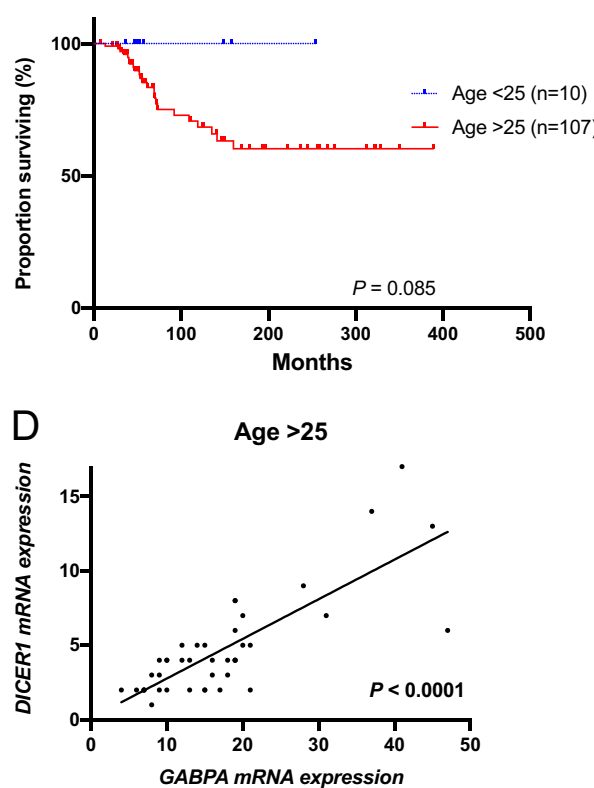

\section{Figure 8}

The age dependent differences in DICER1 expression and survival. (A) DICER1 mRNA expression in patients $>25$ years of age vs $<25$ years of age. (B) The disease-free survival in patients $>25$ years of age vs $<25$ years of age. (C) Correlation of DICER1 and GABPA mRNA expression in patients $<25$ years of age. (D) Correlation of DICER1 and GABPA mRNA expression in patients $>25$ years of age. A full colour version of this figure is available at https:// doi.org/10.1530/ERC-19-0446. confirmed at the protein level with weaker DICER1 immunoreactivity in FTCs compared to corresponding normal thyroid tissues. This observation was even more prominent in older patients and in HuCCs, suggesting that dysregulation of DICER1 could be important in HuCC tumorigenesis and further endorse the separation of FTC and HuCC. Indeed, FTC and HuCC have recently been shown to dissent genetically (Ganly et al. 2013, Gopal et al. 2018, Corver \& Morreau 2019). The DICER1 down-regulation could also explain the observed worse prognosis in HuCC patients in our relatively small cohort, although it is in contrast with previous epidemiological findings that HuCC and FTC exhibit similar prognosis (Bhattacharyya 2003, Nagar et al. 2013). Moreover, the finding of down-regulated DICER1 mRNA in FTAs compared to normal thyroid tissues suggests that aberrant regulation of this gene could be an early tumorigenic event. This assumption is indeed supported by the findings of multinodular goitre as the sole thyroid manifestation in subsets of patients with DICER1 syndrome, suggesting that DICER1 gene aberrancies not always lead to overtly malignant phenotypes.

Previous studies have indicated that GABPA regulates DICER1 through binding of the DICER1 promoter (Yuan et al. 2019), thus acting as a regulator of this gene. In this study, we provide evidence of such an interaction in FTC. First, in our clinical material we observed a strong correlation between GABPA mRNA and DICER1 mRNA expression. This is in line with observations in other types of thyroid cancer including FV-PTCs from the
TCGA database $(\mathrm{r}=0.5467 ; P$ value $<0.001)$ and PTC in our previous report (Yuan et al. 2019). Secondly, after knocking down GABPA, we observed reduced DICER1 expression on mRNA and protein levels in addition to a dysregulated mRNA machinery, and the former association was also visualized by overexpressing GABPA and observing an increase in DICER1 protein levels. Finally, through a ChIP assay we observed for the first time that GABPA indeed binds the DICER1 promoter in FTC cell lines, which was expected given that previous results from our group displayed increased DICER 1 transcriptional activity upon GABPA overexpression using a luciferase reporter in anaplastic thyroid carcinoma cells (Yuan et al. 2019). Collectively, our data suggests that GABPA regulates the expression of DICER1 and contributes to the downstream consequences of dysregulated DICER1 (e.g. miRNA dysregulation, as observed in our cell lines). It should be stressed, however, that although the reduction in GABPA mRNA might explain the attenuated DICER1 mRNA levels observed in our clinical samples, other independent mechanisms might silence the DICER1 translational output. Interestingly, recent findings of oncogenic miR-146b-5p attenuating miRNA biosynthesis by targeting DICER1 and reducing its expression has been implicated in thyroid cancer (Ramirez-Moya et al. 2019). As of this, there might be several synchronous mechanisms operational which all affect the total DICER1 mRNA output.

Furthermore, our data suggest that GABPA regulates DICER1, in turn contributing to increased proliferation in FTC cell lines, as demonstrated by DICER1 depletion 
and overexpression experiments. Intriguingly, in our FTC cell lines, overexpression of DICER1 affected proliferation to a higher extent than DICER1 depletion. The reasons for this discrepancy can only be speculated on, but since endogenous DICER1 protein expression in this cell line is low, augmentation of DICER1 expression might give rise to a greater dose-dependent effect than what would be seen if depleting already low levels of DICER1. A recent study of DICER1 in PTC by RamírezMoya and co-workers showed that down-regulation of DICER1 promoted proliferation, migration, invasion and epithelial-mesenchymal transition through miRNA down-regulation and that DICER1 indeed can act as a tumour suppressor (Ramirez-Moya et al. 2019). These data therefore support our findings of reduced proliferation upon DICER1 overexpression in FTC cell lines and imply that DICER1 could be a tumour suppressor gene of importance in follicular thyroid tumours.

The fact that DICER1 is a key enzyme in the miRNA maturation and that itself is regulated by miRNAs indicates exceptionally intricate mechanisms in DICER1 dysregulation and thyroid tumorigenesis. In FTC cell lines, we observed reduced expression levels of the thyroid-cancer associated miRNA miR-34a-5p upon DICER1 or GABPA depletion, suggesting that components of the miRNA machinery are affected by the general DICER1 down-regulation seen in FTCs. The miR-34a-5p has been shown to exhibit tumour-suppressive properties in PTC, although implicated, the role of $m i R-34 a-5 p$ is not fully understood (Yang et al. 2017). Of potential interest, miR-34a-5p targets MDM4, a p53 regulator that has been found down-regulated in thyroid cancer, with a coupling to advanced stages of the disease (Prodosmo et al. 2008). Moreover, the oncogene MET, which is frequently up-regulated in thyroid cancer, is also a predicted miR-34a-5p target (Ruco et al. 2001).

Clinically, we observed only small differences in survival in low or high DICER1 expressing patients. However, we observed significant couplings between DICER1 expression and patient age, with higher expression in younger patients. The GABPA and DICER1 correlation was also observed in both age groups which indicates that GABPA regulates DICER1 independently of age. Also, as observed before, TERT promoter mutations are more abundant in older patients (Liu et al. 2014). From a traditional molecular genetic perspective, the relationship between GABPA and DICER1 is somewhat puzzling. Given the ambivalent actions of GABPA as a synchronous modulator of the tumour suppressor
DICER 1 and the putative oncogene TERT, there might be dose-depending modes of action at play that we do not fully understand (Yuan et al. 2019). Indeed, the dualistic properties of GABPA in this context and whether it should be regarded as a tumor suppressor or oncogene in thyroid cancer will need to be addressed in future studies.

In summary, DICER1 mutations in commonly mutated regions are rare in FTC but do occur in subsets of young patients. The down-regulation of DICER1 expression, however, seems to be an early tumorigenic event and is at least, in part, regulated by the transcription factor GABPA. The DICER1-GABPA partnership constitutes a novel tumour suppressor axis in FTC with possible implications for future therapeutic interventions using miRNA-based strategies.

\section{Supplementary materials}

This is linked to the online version of the paper at https://doi.org/10.1530/ ERC-19-0446.

\section{Declaration of interest}

The authors declare that there is no conflict of interest that could be perceived as prejudicing the impartiality of the research reported.

\section{Funding}

This work was supported by the Swedish Cancer Society, the Swedish Society for Medical Research, the Cancer Research Funds of Radiumhemmet, Karolinska Institutet and the Stockholm County Council.

\section{Acknowledgements}

The authors wish to thank Dr Dawei Xu for generously providing the GABPA plasmid. Ms Elisabet Ånfalk is acknowledged for retrieving samples from the biobank. Parts of the results are based upon data generated by the TCGA Research Network (https://www.cancer.gov/tcga)

\section{References}

Aschebrook-Kilfoy B, Ward MH, Sabra MM \& Devesa SS 2011 Thyroid cancer incidence patterns in the United States by histologic type, 1992-2006. Thyroid 21 125-134. (https://doi.org/10.1089/ thy.2010.0021)

Bernstein E, Caudy AA, Hammond SM \& Hannon GJ 2001 Role for a bidentate ribonuclease in the initiation step of RNA interference. Nature 409 363-366. (https://doi.org/10.1038/35053110)

Bhattacharyya N 2003 Survival and prognosis in Hurthle cell carcinoma of the thyroid gland. Archives of Otolaryngology: Head and Neck Surgery 129 207-210. (https://doi.org/10.1001/archotol.129.2.207)

Bongiovanni M, Sykiotis GP, La Rosa S, Bisig B, Trimech M, Missiaglia E, Gremaud M, Salvatori Chappuis V, De Vito C, Sciarra A, et al. 2020 Macrofollicular variant of follicular thyroid carcinoma: a rare
(C) 2020 The authors Published by Bioscientifica Ltd. Printed in Great Britain
This work is licensed under a Creative Commons Attribution 4.0 International License.

ded from Bioscientifica com at 04/26/2023 08:31:53AM 
underappreciated pitfall in the diagnosis of thyroid carcinoma. Thyroid 30 72-80. (https://doi.org/10.1089/thy.2018.0607)

Cancer Genome Atlas Research Network 2014 Integrated genomic characterization of papillary thyroid carcinoma. Cell 159 676-690. (https://doi.org/10.1016/j.cell.2014.09.050)

Carlberg M, Hedendahl L, Ahonen M, Koppel T \& Hardell L 2016 Increasing incidence of thyroid cancer in the Nordic countries with main focus on Swedish data. BMC Cancer 16 426. (https://doi. org/10.1186/s12885-016-2429-4)

Chernock RD, Rivera B, Borrelli N, Hill DA, Fahiminiya S, Shah T, Chong AS, Aqil B, Mehrad M, Giordano TJ, et al. 2020 Poorly differentiated thyroid carcinoma of childhood and adolescence: a distinct entity characterized by DICER1 mutations. Modern Pathology [epub]. (https://doi.org/10.1038/s41379-020-0458-7)

Corver WE \& Morreau H 2019 Unique landscape of widespread chromosomal losses in Hurthle cell carcinoma. Endocrine-Related Cancer 26 L1-L3. (https://doi.org/10.1530/ERC-18-0481)

Costa V, Esposito R, Ziviello C, Sepe R, Bim LV, Cacciola NA, DecaussinPetrucci M, Pallante P, Fusco A \& Ciccodicola A 2015 New somatic mutations and WNK1-B4GALNT3 gene fusion in papillary thyroid carcinoma. Oncotarget 6 11242-11251. (https://doi.org/10.18632/ oncotarget.3593)

Cronin KA, Lake AJ, Scott S, Sherman RL, Noone AM, Howlader N, Henley SJ, Anderson RN, Firth AU, Ma J, et al. 2018 Annual report to the nation on the status of cancer, part I: national cancer statistics. Cancer 124 2785-2800. (https://doi.org/10.1002/cncr.31551)

Davies L \& Welch HG 2014 Current thyroid cancer trends in the United States. JAMA Otolaryngology: Head and Neck Surgery 140 317-322. (https://doi.org/10.1001/jamaoto.2014.1)

Esapa CT, Johnson SJ, Kendall-Taylor P, Lennard TW \& Harris PE 1999 Prevalence of Ras mutations in thyroid neoplasia. Clinical Endocrinology 50 529-535. (https://doi. org/10.1046/j.1365-2265.1999.00704.x)

Foulkes WD, Priest JR \& Duchaine TF 2014 DICER1: mutations, microRNAs and mechanisms. Nature Reviews: Cancer 14 662-672. (https://doi.org/10.1038/nrc3802)

Fukahori M, Yoshida A, Hayashi H, Yoshihara M, Matsukuma S, Sakuma Y, Koizume S, Okamoto N, Kondo T, Masuda M, et al. 2012 The associations between RAS mutations and clinical characteristics in follicular thyroid tumors: new insights from a single center and a large patient cohort. Thyroid 22 683-689. (https://doi.org/10.1089/ thy.2011.0261)

Ganly I, Ricarte Filho J, Eng S, Ghossein R, Morris LG, Liang Y, Socci N, Kannan K, Mo Q, Fagin JA, et al. 2013 Genomic dissection of Hurthle cell carcinoma reveals a unique class of thyroid malignancy. Journal of Clinical Endocrinology and Metabolism 98 E962-E972. (https://doi.org/10.1210/jc.2012-3539)

Gopal RK, Kubler K, Calvo SE, Polak P, Livitz D, Rosebrock D, Sadow PM, Campbell B, Donovan SE, Amin S, et al. 2018 Widespread chromosomal losses and mitochondrial DNA alterations as genetic drivers in Hurthle cell carcinoma. Cancer Cell 34 242-255.e5. (https://doi.org/10.1016/j.ccell.2018.06.013)

Hill DA, Ivanovich J, Priest JR, Gurnett CA, Dehner LP, Desruisseau D, Jarzembowski JA, Wikenheiser-Brokamp KA, Suarez BK, Whelan AJ, et al. 2009 DICER1 mutations in familial pleuropulmonary blastoma. Science 325 965. (https://doi.org/10.1126/science.1174334)

Hou P, Liu D, Shan Y, Hu S, Studeman K, Condouris S, Wang Y, Trink A, El-Naggar AK, Tallini G, et al. 2007 Genetic alterations and their relationship in the phosphatidylinositol 3-kinase/Akt pathway in thyroid cancer. Clinical Cancer Research 13 1161-1170. (https://doi. org/10.1158/1078-0432.CCR-06-1125)

James BC, Aschebrook-Kilfoy B, Cipriani N, Kaplan EL, Angelos P \& Grogan RH 2016 The incidence and survival of rare cancers of the thyroid, parathyroid, adrenal, and pancreas. Annals of Surgical Oncology 23 424-433. (https://doi.org/10.1245/s10434-015-4901-9)
Kitahara CM \& Sosa JA 2016 The changing incidence of thyroid cancer. Nature Reviews: Endocrinology 12 646-653. (https://doi.org/10.1038/ nrendo.2016.110)

Kroll TG, Sarraf P, Pecciarini L, Chen CJ, Mueller E, Spiegelman BM \& Fletcher JA 2000 PAX8-PPARgamma1 fusion oncogene in human thyroid carcinoma [corrected]. Science 289 1357-1360. (https://doi. org/10.1126/science.289.5483.1357)

Landa I, Pozdeyev N, Korch C, Marlow LA, Smallridge RC, Copland JA, Henderson YC, Lai SY, Clayman GL, Onoda N, et al. 2019 Comprehensive genetic characterization of human thyroid cancer cell lines: a validated panel for preclinical studies. Clinical Cancer Research 25 3141-3151. (https://doi.org/10.1158/1078-0432.CCR-182953)

Lemoine NR, Mayall ES, Wyllie FS, Williams ED, Goyns M, Stringer B \& Wynford-Thomas D 1989 High frequency of ras oncogene activation in all stages of human thyroid tumorigenesis. Oncogene 4 159-164.

Liu R \& Xing M 2016 Tert promoter mutations in thyroid cancer. Endocrine-Related Cancer 23 R143-R155. (https://doi.org/10.1530/ ERC-15-0533)

Liu T, Wang N, Cao J, Sofiadis A, Dinets A, Zedenius J, Larsson C \& $\mathrm{Xu} \mathrm{D} 2014$ The age- and shorter telomere-dependent tert promoter mutation in follicular thyroid cell-derived carcinomas. Oncogene $\mathbf{3 3}$ 4978-4984. (https://doi.org/10.1038/onc.2013.446)

Lloyd RV, Osamura RY, Klöppel G \& Rosai J 2017. WHO Classification of Tumours of Endocrine Organs WHO/IARC Classification of Tumours, 4th ed., vol. 10. Lyon, France: IARC Press.

Mancikova V, Castelblanco E, Pineiro-Yanez E, Perales-Paton J, de Cubas AA, Inglada-Perez L, Matias-Guiu X, Capel I, Bella M, Lerma E, et al. 2015 MicroRNA deep-sequencing reveals master regulators of follicular and papillary thyroid tumors. Modern Pathology 28 748-757. (https://doi.org/10.1038/modpathol.2015.44)

Marques AR, Espadinha C, Catarino AL, Moniz S, Pereira T, Sobrinho LG \& Leite V 2002 Expression of PAX8-PPAR gamma 1 rearrangements in both follicular thyroid carcinomas and adenomas. Journal of Clinical Endocrinology and Metabolism 87 3947-3952. (https://doi. org/10.1210/jcem.87.8.8756)

Nagar S, Aschebrook-Kilfoy B, Kaplan EL, Angelos P \& Grogan RH 2013 Hurthle cell carcinoma: an update on survival over the last 35 years. Surgery 154 1263-1271; discussion 1271. (https://doi.org/10.1016/j. surg.2013.06.029)

Nicolson NG, Murtha TD, Dong W, Paulsson JO, Choi J, Barbieri AL, Brown TC, Kunstman JW, Larsson C, Prasad ML, et al. 2018 Comprehensive genetic analysis of follicular thyroid carcinoma predicts prognosis independent of histology. Journal of Clinical Endocrinology and Metabolism 103 2640-2650. (https://doi. org/10.1210/jc.2018-00277)

Nikiforova MN, Lynch RA, Biddinger PW, Alexander EK, Dorn GW, Tallini G, Kroll TG \& Nikiforov YE 2003 RAS point mutations and PAX8-PPAR gamma rearrangement in thyroid tumors: evidence for distinct molecular pathways in thyroid follicular carcinoma. Journal of Clinical Endocrinology and Metabolism 88 2318-2326. (https://doi. org/10.1210/jc.2002-021907)

Paulsson JO, Mu N, Shabo I, Wang N, Zedenius J, Larsson C \& Juhlin CC 2018 Tert aberrancies: a screening tool for malignancy in follicular thyroid tumours. Endocrine-Related Cancer 25 723-733. (https://doi.org/10.1530/ERC-18-0050)

Prodosmo A, Giglio S, Moretti S, Mancini F, Barbi F, Avenia N, Di Conza G, Schunemann HJ, Pistola L, Ludovini V, et al. 2008 Analysis of human MDM4 variants in papillary thyroid carcinomas reveals new potential markers of cancer properties. Journal of Molecular Medicine 86 585-596. (https://doi.org/10.1007/s00109-008-0322-6)

Ramirez-Moya J, Wert-Lamas L, Riesco-Eizaguirre G \& Santisteban P 2019 Impaired microRNA processing by DICER1 downregulation endows thyroid cancer with increased aggressiveness. Oncogene $\mathbf{3 8}$ 5486-5499. (https://doi.org/10.1038/s41388-019-0804-8) (c) 2020 The authors Published by Bioscientifica Ltd. Printed in Great Britain
This work is licensed under a Creative Commons Attribution 4.0 International License. ded from Bioscientifica.com at 04/26/2023 08:31:53AM 
Rossing M, Borup R, Henao R, Winther O, Vikesaa J, Niazi O, Godballe C, Krogdahl A, Glud M, Hjort-Sorensen C, et al. 2012 Down-regulation of microRNAs controlling tumourigenic factors in follicular thyroid carcinoma. Journal of Molecular Endocrinology 48 11-23. (https://doi.org/10.1530/JME-11-0039)

Ruco LP, Stoppacciaro A, Ballarini F, Prat M \& Scarpino S 2001 Met protein and hepatocyte growth factor (HGF) in papillary carcinoma of the thyroid: evidence for a pathogenetic role in tumourigenesis. Journal of Pathology 194 4-8. (https://doi.org/10.1002/path.847)

Siegel RL, Miller KD \& Jemal A 2018 Cancer statistics, 2018. CA: A Cancer Journal for Clinicians 68 7-30. (https://doi.org/10.3322/caac.21442)

Slade I, Bacchelli C, Davies H, Murray A, Abbaszadeh F, Hanks S, Barfoot R, Burke A, Chisholm J, Hewitt M, et al. 2011 DICER1 syndrome: clarifying the diagnosis, clinical features and management implications of a pleiotropic tumour predisposition syndrome. Journal of Medical Genetics 48 273-278. (https://doi. org/10.1136/jmg.2010.083790)

Solarski M, Rotondo F, Foulkes WD, Priest JR, Syro LV, Butz H, Cusimano MD \& Kovacs K 2018 DICER1 gene mutations in endocrine tumors. Endocrine-Related Cancer 25 R197-R208. (https:// doi.org/10.1530/ERC-17-0509)
Suarez HG, du Villard JA, Severino M, Caillou B, Schlumberger M, Tubiana M, Parmentier C \& Monier R 1990 Presence of mutations in all three ras genes in human thyroid tumors. Oncogene 5 565-570.

Wang N, Liu T, Sofiadis A, Juhlin CC, Zedenius J, Hoog A, Larsson C \& $\mathrm{Xu}$ D 2014 Tert promoter mutation as an early genetic event activating telomerase in follicular thyroid adenoma (FTA) and atypical FTA. Cancer 120 2965-2979. (https://doi.org/10.1002/ cncr.28800)

Yang LJ, Wang DG, Chen JY, Zhang HY, Zhang FF \& Mou YH 2017 Expression of miR-34a and its role in human papillary thyroid carcinoma. International Journal of Clinical and Experimental Pathology 10 3258-3264.

Yoo SK, Lee S, Kim SJ, Jee HG, Kim BA, Cho H, Song YS, Cho SW, Won JK, Shin JY, et al. 2016 Comprehensive analysis of the transcriptional and mutational landscape of follicular and papillary thyroid cancers. PLoS Genetics 12 e1006239. (https://doi.org/10.1371/ journal.pgen.1006239)

Yuan X, Mu N, Wang N, Straat K, Sofiadis A, Guo Y, Stenman A, Li K, Cheng G, Zhang L, et al. 2019 GABPA inhibits invasion/metastasis in papillary thyroid carcinoma by regulating DICER1 expression. Oncogene 38 965-979. (https://doi.org/10.1038/s41388-018-0483-x)

Received in final form 26 February 2020

Accepted 11 March 2020

Accepted Manuscript published online 11 March 2020 (c) 2020 The authors Published by Bioscientifica Ltd. Printed in Great Britain
This work is licensed under a Creative Commons Attribution 4.0 International License.

ded from Bioscientifica.com at 04/26/2023 08:31:53AM 